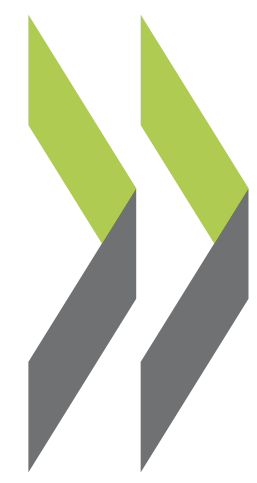

PEB Exchange, Programme on Educational Building 1999/04

\title{
The United Kingdom's \\ School Asset Management \\ Plans
}

\author{
Alan Jones
}

https://dx.doi.org/10.1787/464607560750 


\section{THE \\ UNITED KINGDOM'S SCHO O L ASSET MANAGEMENT PLANS}

Provisional Guidance on Asset M anagement Plans (AMPs) for schools was published by the Department for Education and Employment (DfEE) in August 1998'. These plans will help English Local Education Authorities (LEAs) to identify, agree and address the most urgent and important priorities in their school capital programmes, and to help in their longer term planning and management of the school estate. They will also help to underpin LEA applications to DfEE for capital support. LEAs will be expected to have the first stages of their AMPs in place within about a year, and have them fully operational within two to three years.

\section{Background}

Shortly after coming to power in the May 1997 British election, the Labour government announced its commitment to tackling the school repair and maintenance backlog by increasing capital spending by some $f 1.08$ billion. This, together with $f 1.5$ billion made available following the 1998 Comprehensive Spending Review, as well as private sector investment secured through the Public Private Partnership Programme, will mean that total capital expenditure on premises will have more than doubled by the end of this Parliament. The central aim of this new investment is to help raise standards and attainment in schools through improving the quality of the teaching environment.

\section{Asset management plans}

The aim of AMPs is to set out the information needed, and the criteria used, to make decisions about spending on school premises which raise standards of education and provide value for money.

The objectives of AMPs are to:

- provide an agreed basis for local decisions on spending priorities;

- bring together and co-ordinate the capital needs of other LEA Plans;
- help schools in developing their educational plans by making fair and transparent the process of decision-making across the authority;

- help in the development of public-private partnership projects;

- provide assurance to the DfEE that LEA prioritisation systems are sound;

- provide policy makers with a better national view of the state of the school building stock.

AMPs will cover all capital spending on schools. This will include spending from budgets held centrally by local authorities as well as those delegated to schools.

Five years should be a reasonable time scale for an AMP, with annual updating to reflect changing needs and priorities. This would allow time to programme and budget for repair and maintenance works, and for most small to medium-sized capital schemes. This period also corresponds with the system of quinquennial condition surveys and five year rolling maintenance programmes that many authorities operate. The Plan may, however, need a forward-look element beyond five years for larger scale projects and longer-term public-private partnership schemes.

AMPs will need to develop through a partnership of headteachers, governors and LEAs within a DfEE policy and funding framework. It will be essential for the respective bodies to understand their roles and responsibilities to make the partnership work. AMPs will need to reflect the needs and priorities of individual schools and take account of their educational development plans. LEAs, however, will also have strategic responsibilities that might not al ways match exactly the perceived needs of individual schools. In such circumstances, openness and consultation across all schools will be essential.

\section{Stages in developing an asset management plan}

Six main stages are identified below. Though these are listed sequentially, in reality there will be overlap and interrelationship, both between the different stages and the processes they contain. Furthermore, the whole sequence will need to be regularly reviewed and updated in a cyclical manner as capital programmes are implemented

1. Available from the Department for Education and Employment Publications Centre, PO Box 5050, Sudbury, Suffolk CO106ZQ, UK, Tel.: 44845 6022260, Fax: 448456033360. 
and new programmes are identified. Development of the Plan by the LEA will probably require a multidisciplinary approach involving the Education Department and its property advisers. The LEA will need to ensure that schools and their property advisers are also fully engaged in this process.

Stage 1. Initial policy statement. This sets out the framework of respective roles and responsibilities and the scope of the AMP. It would be worked up with the other partners, and provide the underpinning for the remainder of the Plan.

Stage 2. Assessing existing premises. This involves assessing the total ity of the existing school premises in the area and gathering key data and premises performance indicators. To aid this process, and to help ensure national consistency, the DfEE will shortly be issuing guidance on these aspects (see "Next steps" below).

Stage 3. Identifying needs. This stage involves considering LEA Plans and School Development Plans; determining the "gap" between existing provision and current needs; and identifying areas of concern. The investment needs of school premises can be categorised broadly in terms of condition, sufficiency and suitability as follows:

- condition needs focus on the physical state of premises to ensure safe and continuous operation;

- sufficiency needs focus on the quantity and organisation of school places;

- suitability needs focus on the quality of premises to meet curriculum or management needs and other issues impacting on the role of the LEA in raising education standards.

Although described separately, in real ity more than one of these elements may be addressed in a single project. For example, many of the advantages gained by designing suitability for curriculum into buildings should be achieved through projects which have been funded to tackle deficiencies in condition or to provide places.

Stage 4. D etermining priorities. Using information provided in Stages 2 and 3, and in consultation with the other partners, LEAs will need to seek a consensus on local premises priorities. To enable schools to focus their funding applications on those areas which are most likely to attract funding, it may be hel pful for the LEA to set out the agreed priorities in standard formats and circulate copies to schools.
Stage 5. Feasibility studies and option appraisal. This stage involves establishing the feasibility of alternative potential solutions to priority problems. For larger projects, consideration of a range of options isneeded for a rationally based decision. Two "baseline" options would be the "status quo" and "do minimum" options. For each option, analysis of the main costs and benefits will establish the most effective and economic solution. This will normally involve the use of investment appraisal techniques.

Stage 6. Implementation, review and evaluation. Implementation. In this stage, favoured options are further developed, funding and procurement issues are finalised, and approved schemes would be included with the appropriate capital programmes of LEAs or schools. On completion of new works, and consistent with good stewardship of the premises, LEAs/schools should draw up and implementplanned maintenance programmes. Similar programmes should be put in place for existing school premises.

Review. AMPsare dynamic in nature. The outcomes from capital and maintenance programmes will therefore need to be reflected within the ongoing updating and review of the Plan, in terms of reprioritisation of projects, identification of new needs, etc.

Evaluation. It will be necessary to evaluate how well the Plan has worked in practice, some two or three years after introduction, in the first instance. As part of this process, the nature of the local situation at the outset will need to be clear to ensure that the effect of the Plan can be separated from underlying factors.

\section{How D fEE will use LEA AMPs}

Over time, DfEE plans to increasingly use the evidence from AMPs to inform the national distribution of capital resources for schools, and makelessuse of theone-off, mainly annual, bidding systems that have operated in recent years.

A key output from the AMP would be a prioritised programme, regularly updated, of projects that address the most serious and urgent needs of the LEA's school building stock in terms of condition, sufficiency and suitability. Where this is underpinned by a sound planning process, DfEE would aim to be able to respect those priorities and allow LEAs to tackle their needs with no further intervention from the Department. DfEE's intervention could then be in inverse proportion to LEAs' success in developing and maintaining an effective AMP process. 
The DfEE will need to ensure that applications from LEAsfor capital supportare soundly based. Mechanisms are therefore planned to assess the robustness of AMPs. These will need to cover the quality of the Plan itself and of the underlying processes. These will include:

- the thoroughness of the LEA's consultations with schools;

- the commitment the LEA has secured from schools to the way it approaches the assessment of their premises;

- the objectivity, transparency and fairness with which the LEA prioritises capital applications across all schools;

- the realism of the LEA's plans to maintain and monitor the development of the AMP.

\section{Next steps}

To facilitate the development of AMPs, the DfEE will be shortly publishing further guidance on standard methods for assessing the condition, sufficiency and suitability of school buildings. Guidance will also be produced to encourage the devel opment of a common framework for property information systems in LEAs.

\section{ALBANIAN MODEL SCHOOL}

The school soon to be completed in Paskuqan, a suburb of Tirana, was created to meet the present and changing needs of the community. The long-lasting, flexible structure designed to stimulate learning is the result of a close collaboration between pedagogical and building experts. The Albania Education DevelopmentProject (AED) of the Soros Foundation has financed the school - for pupils in the first eight years of education - as part of its larger programmeto foster the country's educational system.

\section{Design for education}

The design team has taken care to maintain structural quality while providing for the school's educational and extra-curicular vocations. The building's interior and exterior environments are expressly planned to facilitate the work of the pupils and teachers. Centred upon efforts of modernisation, the construction exceeds currentAlbanian building standards.

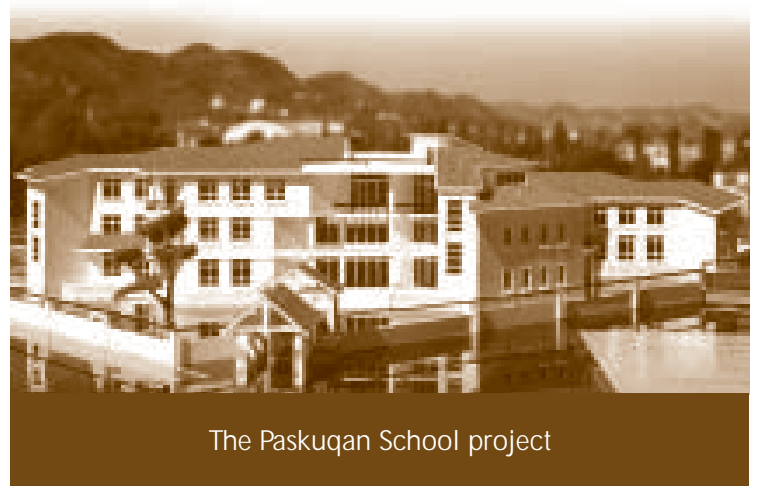

The final blueprint was chosen because of its composition of functional units. Teaching areas, administrative offices, faculty rooms and sports facilities are grouped according to function. Elementary grades (ages six to nine) and junior secondary grades (ages ten to thirteen) are separated but share an administrative centre, a central multifunctional hall and a gymnasium. Each grade system has its own entrance, and its classrooms communicate internally; the corridors of both sections lead to a spacious multifunctional area that can be used by part or all of the school for meetings, festivals or recreational activities. Administrative offices are located on each of the three floors of the building conveying easy access, while they are also connected by an independentstaircase. The school's functional sections, in addition to offering independence, has facilitated construction in stages.

The project allows for a variety of teaching possibilities. Of vital importance is the classroom, where students leam through group work, experimentation and independent research. The architect was sensitive to the directinfluence of a room's physical qualities on the effectiveness of teaching such as its size, shape, height, lighting, colour and fumiture. Each of the sixteen classrooms is rectangular with a capacity of 30 seats and a surface area of $1.4 \mathrm{~m}^{2}$ per student Fumitureand equipmentcan bearranged for various purposes depending on the subject of study and the teaching method. Classroom layout for the social sciences, for instance, encouragesconversation and interaction. For the natural sciences, the layout gives priority to working individually and in small groups. Five special study rooms (e.g. physics and chemistry laboratories) provide greater possibilitiesfor experimental work.

Corridors, perceived by the architect as an indispensable means of communication, were designed with optimum dimensions for comfortable movement A central staircase connects all of the floors, and each school cycle has its own staircase 